\title{
Retraction Note: Characteristics of air pollution and environmental economic efficiency in Beijing-Tianjin-Hebei and surrounding areas
}

\author{
Jinsong Meng ${ }^{1} \cdot$ Maoxuan Wang $^{1} \cdot$ Xiaokaiti Xuekelaiti $^{1}$
}

Published online: 22 November 2021

C) Saudi Society for Geosciences 2021

Retraction Note: Arabian Journal of Geosciences (2021) 14: 1072 https://doi.org/10.1007/s12517-021-07389-5

The Editor-in-Chief and the Publisher have retracted this article because the content of this article is nonsensical. The peer review process was not carried out in accordance with the Publisher's peer review policy. The authors have not responded to correspondence regarding this retraction.

The original article can be found online at https://doi.org/10.1007/ s12517-021-07389-5.

Xiaokaiti Xuekelaiti

prtoli@163.com

1 School of Government, Beijing Normal University, Beijing 100875, China 